\title{
Neuropsychological Profiles of Neglected Children
}

\author{
Isabelle Frigon, ${ }^{*}$ Christian C. Joyal, and Pierre Nolin \\ Department of Psychology, Université du Québec à Trois-RivièresTrois-Rivières, Québec, Canada
}

*Corresponding author: Christian C. Joyal, Department of Psychology, Universitédu Québec à Trois-Rivières, 3351, boul. des Forges, C.P. 500, Trois-Rivières G9A 5H7, Québec, Canada, Fax: 819-376-519, Tel: 819-376-5011-3559, E-mail: christian.joyal@uqtr.ca

Citation: Isabelle Frigon,Christian C. Joyal, and Pierre Nolin (2018) Neuropsychological Profiles of Neglected Children. J Neurosci Neuropsyc 2: 202

Article history: Received: 07 June 2018, Accepted: 05 July 2018, Published: 09 July 2018

\begin{abstract}
Background: Although maltreatment is associated with a wide array of cognitive impairments, few neuropsychological data are available concerning neglected children. Because they represent a highly heterogeneous group, the main goal of this study was to identify cognitive profiles in neglected children using valid neuropsychological measures.

Method: One hundred and forty-three children (74 boys and 69 girls) aged from 6 to 12 years and involved with Child Protection Services for parental neglect were individually evaluated for research purposes. Profiles were obtained through cluster analyses based on neuropsychological measures assessing motor inhibition, resistance to distractors, receptive language, verbal fluency, visual memory, verbal memory, planning, problem solving, abstraction, and integrated executive functions.
\end{abstract}

Results: Five cognitive profiles emerged from the analyses, characterized with either: 1) generalized impairments on all cognitive functions; 2) lower inhibition, verbal memory, problem solving, abstraction and integrated executive functions; 3 ) difficulties with resistance to distractors and verbal memory; 4) deficits in verbal fluency and verbal memory; or 5) preserved performances in all cognitive functions.

Conclusion: Overall, the present study confirms that a high cognitive heterogeneity exists among neglected children and it provides a better description of more specific profiles. These results should help establishing more specific neuropsychological treatment plans.

Keywords: Child Abuse; Child Neglect; Physical Abuse; Neuropsychology; Cognitive Profiles

\section{Introduction}

Parental maltreatment is a well-documented phenomenon with potentially serious and long lasting consequences at physical, psychological, cognitive and/or academiclevels [1-5]. Although alinkbetween maltreatment and the presence of neurodevelopmental anomalies is strongly suggested, very few exhaustive neuropsychological studies have been carried out with maltreated children [6-11]. With neglected children, neuropsychological evidence-based data are even rarer [12,13]. Given that neglect represents the most frequent type of maltreatment, and that very few neuropsychological data exist for these cases, the aim of this study was to identify cognitive profiles in neglected children using a large range of standardized neuropsychological tests [14]. This might help suggesting more targeted cognitive interventions, in line with the specific profile of a given child.

\section{Maltreatment and cognition}

Several maltreatment studies report a wide array of associated cognitive disorders, encompassing attention, memory, language, intellectual functioning, and executive functions [6,13,15-17]. However, not all maltreated children are affected by these deficits, and all these deficits rarely affect a single person, so that no "neuropsychological syndrome » exists for childhood maltreatment, and there is no characteristic cognitive sequela. In fact, neuropsychological profiles associated with childhood maltreatment are known to be highly heterogeneous [7]. While certain victims are heavily affected by the number and severity of symptoms, others seem affected only in a few cognitive areas, whereas still others seem largely spared, if not resilient [2,11,13,18-21]. Therefore, different cognitive profiles co-exist within this population and it would be clinically helpful to document them.

This heterogeneity reflects the complex link between maltreatment and cognitive functions. Several factors - including the type of maltreatment itself- influence the development neuropsychological capacities. For instance, neglect will have a different effect on cognitive functions when the child also suffered from physical abuse [7]. Other factors (personal, parental and environmental) more or less present from one case to another, are commonly associated with maltreatment and can contribute to jeopardizing cognitive, psychosocial and neurological development (e.g. symptoms of a post-traumatic streess disorder) [12]. Each of these 
variables (and others) can influence the child's neurological and cognitive development, leading to different neuropsychological profiles [20].

\section{Neglect and cognition}

Few neuropsychological studies have dealt specifically with neglected children [12]. Available data typically rely on the more general measures of school performance or large scales, which generally indicate language deficits (receptive and expressive) and a below-optimal cognitive development at school entry age.

Nolin and Éthier [13] observed that by using a complete battery of validated neuropsychological tests and controlling for different socio-demographic factors (age, sex, neighborhood, school, education and family revenue), the difference between neglected and non-neglected children reflect basic dysfunctions: manual dexterity, visual-motor skills and attention. By contrast, neglect with physical abuse was associated with much greater deficits than neglect alone, including higher executive dysfunctions (planning, problem solving and abstraction). Thus, the accumulated effects of maltreatment types, well documented at the psychopathological level should also involve cognitive development [22-32].

A variety of profiles. Although few studies concerned with neglected children include complete and valid neuropsychological evaluations, some investigative clues are available. First, the heterogeneity of cognitive profiles associated with childhood maltreatment should also characterize neglected children. For instance, children victims of both neglect and another type of maltreatment (e.g., physical abuse) should present a relatively poorer cognitive profile [13]. Second, some neglected children might be considered resilient and present a picture without any significant cognitive disorders [19]. Indeed, some maltreated children possess comparable cognitive capacities, if not superior, to normative data or controls $[11,13,33]$.Third, cognitive profiles traditionally associated with certain mental or developmental disorders can also be observed because of their high prevalence in maltreated children (e.g. Post-Traumatic Stress Disorder, PTSD; Attention Deficit Hyperactive Disorder, ADHD; Intellectual Disability; Behavioral and Aggressivity Disorder; [15,18,34-36]). For example, Beers \& De Bellis [15] reported reported significant deficits in vigilance, cognitive inhibition, verbal fluency and executive functions in 14 maltreated children affected by PTSD compared to 15 non-maltreated children of similar socio-demographic level [12]. This picture reflects neuropsychological profiles traditionally associated with PTSD (i.e. concentration, attention and memory disorders)[37]. Neuropsychological disorders associated with ADHD (e.g. Barkley, 1997; Pennington, 2005; Nigg, 2005; Sonuga-Barke, 2005) could also emerge in profiles linked to maltreatment. Deficits in memory are noted in maltreated children too [42-43]. Thus, maltreatment does not affect cognitive development in a specific way, and the quest for a unique or characteristic neuropsychological profile of maltreated children has been unsuccessful so far. Defining the number and nature of neuropsychological profiles associated with neglect would help to better describe the cognitive deficits, to stress their heterogeneity to underline their possible co-occurrence, and to offer treatment plan better suited to the needs of a given individual.

Aims and hypotheses: The main goal of this study was to assess a relatively high number of maltreated children with a battery of standardized neuropsychological tests to perform multivariate cluster analyses. This approach by deficits would allow determining the number and nature of cognitive profiles associated with parental maltreatments which, in turn, would lead to a substantial refinement of our knowledge concerning the cognitive areas that might contribute to the difficulties of neglected children. Due to the possible cumulative effects between the different types of maltreatment, a second aim was to verify whether neglected children with physical abuse generally presented a greater range of deficits.

Four hypotheses were stated a priori: (1) Due to the high number of factors involved in the link between neglect and cognitive development, neglect should be associated with several neuropsychological profiles of varied severity; (2) For the same reasons, it is expected that neglected children with and without physical abuse will be found in each of the profiles; (3) However, due to the possible cumulative effect of maltreatment types, a greater number of child victims of neglect and physical abuse should be described by highest affected profile; (4) Finally, a subgroup of resilient children at the cognitive level should present a profile without significant disorders, which should include a larger number of neglected children only.

Method

\section{Participants}

One hundred and ninety-three neglected children between 6 and 12 years old were recruited for the present study. All were French-speaking, living in the province of Quebec, and followed by Child Protection Services (CPS) for parental neglect. The research was explained to a parent by CPS caseworkers, and signed consent forms were obtained (this project was approved by the ethical Committee of the Université du Québec à Trois-Rivières). Children with mental deficiencies ( $\mathrm{n}=22)$, congenital or acquired neurological illness $(n=8)$, and/or suffering from sexual abuse $(n=24)$ were excluded. Therefore, the final sample of participants consisted of 143 children ( 74 boys and 69 girls, 6-12 y.o.; $9 \pm 2$ on average).

\section{Instruments}

Types of neglect: The type of neglect was determined from the classification recorded in the CPS files, as well as a thorough analysis 
of data collected through questionnaires completed by the parents who gave information about the presence of physical abuse. Given that comorbidity between different types of maltreatment commonly occurs, additional questionnaires concerning other types of abuse were included (see below). Children were considered neglected with physical abuse when they were determined by the CPS to have experienced physical abuse or if any information on questionnaires revealed they have been physically abused in addition to neglect. When the CPS determined children to be neglected without any sign of abuse based on an analysis of the information gathered, they were assigned to be neglected only. An undergraduate research assistant verbally assessed these questionnaires to parents:

1) Information concerning the child's environment. This homemade questionnaire covers a set of areas related to the child's initial development (mother's health, substance abuse, childbirth, child's health, life events, etc.).

2) Parents-Child Conflict Tactics Scales (PCCTS) French version [29]. This instrument specifies the type of disciplinary behaviour preferred by the parent for the child [non-violent discipline, psychological aggression, physical violence (corporal punishment) and serious or extreme violence] and measures how disagreements and disputes are solved within the family.

3) Child Abuse Potential Inventory (CAPI) [45-46] French translation by Palacio-Quintin[47]. The instrument consists of 160 questions for the parent, generating seven clinical subscales: potential of global abuse, distress, rigidity and sadness, problems with children, family and others. Responses provide a score of the parent's abuse potential (scaled scores could be between 0 and 486 ; a score of 166 or higher is considered significant).

Socio-economic status: The Hollingshead Social Status Index was used to measure socio-economic status. Both parents' education and profession were taken into account in order to attribute a classification corresponding to their social status [48]. An average of the classification attributed to each parent was calculated. When average was less than 47 , the socio-economic status was considered elevated.

Neuropsychological evaluation: All children completed a composite battery of ten neuropsychology tests selected for research purposes (i.e., data were not obtained from clinical files).

1. The Knock and Tap subtest of the NEPSY [49] assesses the ability to inhibit acquired manual motor responses and to resist natural tendency to imitate (motor inhibition). This subtest is scored for accuracy [49]. Raw scores were converted to age-scored percentile ranks $(M=26-75)$.

2. The Statue subtest from the NEPSY [49]. This test measures resistance to distractors, motor perseverance and impulse inhibition (self-regulation). This executive measure requires the child to remain motionless, despite the presence of several distractors. This subtest is scored for fidelity. Raw scores were converted to age-scored percentile ranks $(M=26-75)$.

3. The Comprehension of Instructions subtest of the NEPSY assesses receptive language and the ability to process and respond to verbal instructions of increasing syntactic complexity (receptive language) [49]. This subtest is scored for fidelity. Raw scores were converted to age-scored standard scores. The scale is from 1 to $20(\mathrm{M}=10, \mathrm{SD}=3)$.

4. The Verbal Fluency subtest, also from the NEPSY measures the child's ability to produce words with semantic or phonemic categories (verbal fluency) [49]. This is therefore a measure which evaluates several language spheres, including vocabulary, lexical access, using recuperation strategies, and verbal working memory. This subtest is scored for accuracy. Raw scores were converted to age-scored standard scores. The scale is from 1 to $20(\mathrm{M}=10, \mathrm{SD}=3)$.

5. The Dot Location subtest of the Children Memory Scale requires visual memory. This test is scored for accuracy [50]. Raw scores were converted to age-scored standard scores. The scale is from 1 to $20(\mathrm{M}=10, \mathrm{SD}=3)$. This subtest has good psychometric properties for its validity and fidelity [50].

6. The French version of the California Verbal Learning Test for Children (CVLT-C,) [52]: a verbal memory measure requires the child to memorize words. The results used for the study correspond to the total number of words remembered in attempts. French Canadian norms were used. This test possesses good validity and fidelity properties .

7. The Tower of the NEPSY assesses the ability to plan, control and self-regulation (planning). This subtest is scored for accuracy. Raw scores were converted to age-scored standard scores. The scale is from 1 to $20(\mathrm{M}=10, \mathrm{SD}=3)$.

8. The Arithmetic Subtest from WISC-III assesses the child's ability to solve mathematical problems of increasing difficulty (problem solving). The test calls for mental calculation and working memory. This subtest is scored for speed and accuracy. Raw scores were converted to age-corrected standard scores $(\mathrm{M}=10, \mathrm{SD}=3)$.

9. The Similarities Subtest from WISC-III requires the child to find certain common characteristics between two concepts (abstraction). This calls for abstract thought [53]. This subtest is scored for accuracy. Raw scores were converted to age-corrected standard scores $(\mathrm{M}=10, \mathrm{SD}=3)$.

10. The Auditory Attention and Response Set task (NEPSY), assesses several generally associated executive functions: sustained attention, shared attention, cognitive flexibility and working memory [49]. The primary aim of this test is to measure the integrity of 
complex executive functions in children, that is, to learn a pattern of complex responses, modify the acquired behaviour, maintain and adapt it to new requirements. The child must therefore change a learned response pattern, which requires good inhibition and flexibility abilities, in addition to remembering new instructions (working memory) and ignoring the old. This subtest is scored for speed and accuracy. Raw scores were converted to age-scored standard scores. The scale is from 1 to $20(\mathrm{M}=10, \mathrm{SD}=3)$. For all NEPSY tasks, psychometric properties in terms of validity and fidelity are available in [54].

Procedure: The evaluation took place at the school of the child, in a closed room, individually with the evaluator. Two hours were necessary to complete the evaluation (including two short breaks), and the test order was counter-balanced to control for any fatigue factor. Children of 10 years or older signed a consent form (in addition to the parent), whereas those under 10 gave verbal consent, as recommended by the ethical committee. Testing was conducted by undergraduate students who had received 10 hours of training dealing with administrative procedures. All had received an instruction manual and a supervisor was on hand. Participants were distributed randomly among the students by the research professional in charge of the project. Tests were corrected by a graduate student and attested by a second graduate student prior to entering the data on SPSS.

Data Analysis: Descriptive analyses were initially carried out to describe the sample. To classify data according to relationships, a cluster analysis was conducted. This is a group of multivariate techniques whose primary purpose is to assemble objects based on characteristics they possess. It is the only multivariate technique that does not estimate the variance empirically but uses it as specified by the researcher [55]. This technique has the advantage to generate clusters that are not influenced by preconceived notions with regard to defining characteristics. Ward's method, a hierarchical agglomerative approach which minimises withincluster variance at each stage of grouping, was used for this study [56]. It is considered one of the most effective clustering algorithms for recovering underlying structure [57-59]. Ward's method has performed well in terms of replicability, and it is considered to be resistant to the effects of outliers compared with other agglomerative clustering techniques [55,60-62]. Squared Euclidean Distance was chosen as the measure of similarity to obtain subgroups' homogeneity [63]. It is known to be sensitive to both profile level and patterns, whereas alternative methods such as correlations coefficients are insensitive to level of performances differences [57,6466]). In line with previous studies, certain criteria were established to determine the optimal solution. First, intra and inter group variabilities were considered to choose the solution with both a minimal intra group variants and maximal extra group variants. The solution also had to be interpretable from clinical and theoretical points of views [54]. Finally, each group had to represent at least $5 \%$ of the total sample $(n \geq 7)[67]$.

Between-group mean comparisons and Chi-squared tests were also conducted to verify whether descriptive variables [sex (male/ female), intellectual functioning, type of neglect (with/without physical abuse) and socio-economic status] contributed significantly to the classification of participants to a particular profile.

\section{Results}

Socio-demographic data: From our sample of 143 children, 94 suffered from neglect with physical abuse, and 49 experienced neglect only. All participants came from weak socio-economic environments, as calculated by the Hollingshead Index $(\mathrm{M}=65.7 \pm 9.3)$ and the potential of abuse was clinically significant.

Profile description: Grouping analyses were based on neuropsychological results. Total scores of neuropsychological tests were transformed into $\mathrm{z}$ scores to facilitate comparison. Four solutions, consisting of three to six subgroups were generated and the best solution was that of five subgroups. A reliability check was conducted using the complete linkage procedure and the same results were obtained.

The five profiles are presented and described hereafter Profile 1 ( $n=7 ; 5$ males and 2 females) is characterized by a relative weakness in almost all of the cognitive tests, including measures of motor inhibition (Knock and Tap), resistance to distractors (Statue), receptive language (Comprehension of Instructions, verbal fluency (Verbal Fluency), visual memory (Dot Location), verbal memory (CVLT-C), planning (Tower), problem solving (Arithmetic), abstraction (Similarities) and integrative executive functions (Auditory Attention and Response Set). Based on the generalized disorders, this profile was named "extended deficits". Profile 2 ( $n=20 ; 15$ males, 5 females) refers to children with weaker scores of motor inhibition, verbal memory, problem solving, abstraction and integrative executive functions. These children are able to resist to distractors, as they had good results on the Statue task. Due to the prominent picture of executive dysfunctions, this profile was named "dysexecutive". Profile 3 ( $\mathrm{n}=18 ; 10$ males, 5 females) describes good abilities in motor inhibition (Knock and Tap), but deficits in resistance to distractors (Statue) and verbal memory. In these cases, a posteriori analyses were conducted to verify whether these children differed from the other profiles in the number of false positives or false negatives in the recognition mode (CVLT-C). In fact, this profile gave significantly more false positives in recognition mode than profiles 1 and 4, which is generally associated with difficulty to distinguish words among distractors (sensitivity to interference[65]). Given that resistance to external distractors is weak within this profile, it is called "vulnerable concentration". Profile 4 ( $\mathrm{n}=55 ; 25$ males, 30 females) only presents a relative weakness the lexical access and vocabulary (Verbal Fluency), and verbal memory (CVLT-C). Therefore, this profile was labelled "verbal weakness". Finally, Profile 5 (n=43; 19 males, 24 females) presented no significant cognitive deficit, all results being within the limits of standard averages. Thus, the profile was named "without difficulty". 


\begin{tabular}{|c|c|c|c|c|c|c|c|c|}
\hline & $\begin{array}{c}\text { Cluster } 1 \\
n=7\end{array}$ & $\begin{array}{c}\text { Cluster } 2 \\
n=20\end{array}$ & $\begin{array}{c}\text { Cluster } 3 \\
n=18\end{array}$ & $\begin{array}{c}\text { Cluster } 4 \\
n=55\end{array}$ & $\begin{array}{c}\text { Cluster } 5 \\
n=43\end{array}$ & Test & p & Contrats \\
\hline Age M (S.D.) & $115.9(30.1)$ & $128.7(22.6)$ & $112.56(28.1)$ & $111.9(24.1)$ & $124.5(23.14)$ & $\mathrm{F}=2.79$ & .03 & $\begin{array}{c}\mathrm{C} 1>\mathrm{C} 3, \mathrm{C} 5 \\
\mathrm{C} 3<\mathrm{C} 4\end{array}$ \\
\hline $\begin{array}{l}\text { Sex ratio } \\
\text { (boys/girls }\end{array}$ & $5 / 2$ & $15 / 5$ & $10 / 8$ & $25 / 30$ & $19 / 24$ & $\mathrm{X}^{2}=5.4$ & .04 & $\mathrm{C} 1 \neq \mathrm{C} 3, \mathrm{C} 4$ \\
\hline Education & $3(2.7)$ & $3.9(1.6)$ & $3.11(2.1)$ & $4.07(1.8)$ & $4.02(1.8)$ & $\mathrm{F}=2.09$ & .09 & \\
\hline I.Q. & $91.6(20.6)$ & $93.6(12.1)$ & $98.6(17.7)$ & $97.4(12.4)$ & $99.7(12.3)$ & $\mathrm{F}=1.03$ & .39 & \\
\hline $\begin{array}{l}\text { Hollingshead } \\
\text { Index }\end{array}$ & $70.3(3.6)$ & $63.1(11.4)$ & $65.4(9.8)$ & $66.2(8.9)$ & $65.6(9.4)$ & $\mathrm{F}=.8$ & .53 & \\
\hline $\begin{array}{c}\text { Physical abuse } \\
\text { without/ } \\
\text { with }\end{array}$ & $2 / 5$ & $7 / 13$ & $3 / 15$ & $18 / 37$ & $19 / 24$ & $\mathrm{X}^{2}=0.03$ & .9 & \\
\hline
\end{tabular}

Table 1: Between-group comparisons with socio-demographic variables (Mean and Standard deviation)

Variance analyses and non-parametric tests: No significant difference emerged between the groups for the type of neglect (with or without physical abuse), mean IQ, and Hollingshead Index (Table 1). Significant differences emerged for age (mean age for "dysexecutive" cluster was higher than that of "vulnerable concentration" and "verbal weakness" clusters; mean age of "verbal weakness" was lower than that of "without difficulty" cluster), and sex (boy/girl ratio was significantly higher for boys in the "dysexecutive" cluster and higher for girls in the "verbal weakness" and "without difficulty" clusters).

\section{Discussion}

The main objective of this study was to evaluate neglected children with a battery of validated neuropsychological tests to identify their cognitive profiles. As expected, neglected children presented heterogeneous neuropsychological profiles. Five profiles of varied severity emerged, which were situated on a continuum from generalized cognitive deficits to no significant cognitive impairment. The second objective was to verify whether neglect with physical abuse was associated with a higher number and more serious neuropsychological deficits than neglect alone. This hypothesis was not confirmed. The results are discussed below.

\section{Five neuropsychological profiles linked to neglect}

Profile 1, called "extended deficits", describes children who present the widest range of deficits. As expected, this profile represents the smallest subgroup ( $n=7$ or $5 \%$ of the sample) but, contrary to the hypothesis, it does not statistically contain more neglected children with physical abuse $(n=5)$ than those without physical abuse $(n=2)$. This does not actually mean that both subgroups are necessarily equivalent. First, this profile deals with a very small number of children, and the absence of difference may be due to a lack of statistical strength. A harmful added effect seems therefore plausible among the different types of maltreatment for cognitive development, just as it was observed for other forms of development (physical, psychological or social )[29]. Future studies with a larger number of maltreated children will allow confirmation of the cumulative effect at the cognitive level.

Profile 2 ("dysexecutive") describes more pronounced deficits at the executive functions level. Verbal memory is also affected, perhaps due to executive disorders [38]. It should be noted that this type of clinical picture associated with executive function deficits is generally linked to ADHD with a particularly high incidence among neglected children [36,69-72]. Moreover, this profile involves a majority of boys (15/20 or 75\%), which is also the case for ADHD (about 3 boys for every girl)[38]. Although the present data do not allow determining whether this subgroup was actually affected by ADHD, their profiles could be similar. These results also remind those of Beers \& De Bellis, who reported that maltreated children and adolescents with PTSD showed deficits in executive functions level, including attention functions and abstract thinking. It seems therefore that the neuropsychological pictures associated with ADHD or PTSD could describe certain neglected children [15]. Future studies should confirm this link between neglect, executive dysfunctions and psychopathologies.

Moreover, a widely-accepted neuropsychological hypothesis in the field of ADHD stipulates that executive function deficits of ADHD children of hyperactive or mixed types can be largely explained by their fundamental disorders of motor inhibition[33]). Since motor impulsiveness (also aggressivity; e.g. may be present in neglected children, it would be interesting to recruit a large enough number of subjects to carry out regression analyses to identify more precisely the influence of impulsiveness on other executive functions.

Profile 3 ("vulnerable concentration") is characterized by more specific deficits: difficulties at resisting external distractors, weak word recall during memory task (CVLT), and a high number of false positives in recognition, closely linked to ADHD. Contrary to Profile 2 ("dysexecutive"), children of this profile ("vulnerable concentration") show good capacity for motor inhibition as measured by the Knock \& Tap test, as well as aptitudes kept for other executive functions (i.e. flexibility, reasoning and abstraction). It would be possible, therefore, that Profiles 2 and 3 describe different subgroups of neglected children meeting the diagnostic criteria of ADHD. One could speculate that Profile 2 describes a ADHD-M (mixed) or ADHD (hyperactive) subgroup, while Profile 3 would be concerned more with an ADHD (inattention) subgroup since similar differences of a neuropsychological picture 
can be found in these subgroups of ADHD children without a history of neglect (see [39] for a brief presentation of the data and [73] for the neuropsychological validity of these subgroups with the NEPSY battery).

It is equally interesting to draw a parallel between Profiles 2 and 3 of the present study and the theory on maltreated children's personality disorders by Cicchetti and collaborators [30]. These authors describe the different developmental trajectories of maltreated children based on two main axes: level of Ego control and Ego resiliency. A high level of Ego control is observed when the child is able to handle his impulsions and accept a delayed reward. A high level of Ego resiliency refers to a good capacity of affect and behavioural regulation as well as flexible use of problem-solving strategies. Inhibition, resistance to distractors, flexibility and problem solving represent executive functions in neuropsychology and are all more or less affected within Profiles 2 and 3. This theoretical framework [30] could therefore be used in the future with the help of a battery of exclusively executive neuropsychological tests. Moreover, this would allow establishing strengths and weaknesses related to each executive function and their influence on the others, in order to help establish treatment and intervention plans better adapted to children of Profiles 2 or 3.

Profile 4 ("verbal weakness") is based on significantly poorer results in verbal fluency and verbal memory, which depends on vocabulary, lexical access, learning, the use of efficient strategies of recall and verbal working memory. These data are coherent with previous studies which revealed the incidence of language difficulties in neglected children. Broomand [74] had also identified a deficit at the verbal fluency level in a sample of physically abused children [75]. Expressive language disorders as well as disorders in more than one language sphere have also been documented in other studies $[23,76,77]$.

Profile 5 ("without difficulty") did not show any apparent deficit in tests. Thus, in line with the fourth hypothesis, some neglected children do not present any significant cognitive deficits. These results could be explained by a capacity for resilience that some maltreated children possess, which has often been demonstrated at the psychosocial and psychiatric levels [1,2,19,72]. Interestingly, the fourth hypothesis is not totally confirmed, since a statistically equal number of neglected children with physical abuse (24) and neglected only children (19) were considered "resilient" at the cognitive level here. This surprising result well reflects the great heterogeneity of neglected children's cognitive profiles, as well as a large number of factors involved in the link between neglect and cognitive development. In fact, about $25 \%$ of neglected and physically-abused children in the present study do not show significant neuropsychological disorder. It is therefore possible and relatively probable to encounter in the clinic a neglected and abused child but well performing at the cognitive level.

These results justify the importance of conducting research which deals with predictive factors of resilience much as with deficits and risk factors linked to neglect [20]. Identification of factors predicting resilience could contribute to directing preventive interventions to be prescribed for this population.

Overall, results of the present study support the idea of individual heterogeneity linked to neglect. Results also demonstrate that the nature of the harm as a stress indicator is not the sole predictor of the cognitive profile. These results nonetheless support previous work from authors who suggested a link between severe stress and the changes in cerebral structures and functions in children victims of physical or sexual abuse [2,6,15,78-81]. Shore [81] proposed links between maltreatment, lack of care, severe attachment defects, and early neurodevelopmental anomalies of the right hemisphere systems in the face of stress. Relational trauma experienced by neglected children would, through modifications of the right hemisphere's functioning, underlie certain cognitive deficits found in this population, especially at the self-regulation level.

The present research, through its approach using clusters analysis, differs from previous studies by demonstrating that not all neglected children have cognitive deficits. Results support the idea that multiple risk factors other than neglect co-exist and can compromise cognitive development, but also support the opposite idea, that protection factors can intervene and prevent the harmful effects of neglect. Longitudinal studies of cohorts will allow further documentation of characteristics of these children who, despite the presence of adversity, develop positively. The link between neglect and resilience should therefore be further investigated, in order to help guide interventions in a more specific manner, in accordance with needs identified for each child. Results of the study justify the development of distinct clinical approaches, both at the theoretical level as well as by direct intervention.

\section{Limits of the study}

Insofar as the factors linked to maltreatment, the present study does not include a variable allowing the documentation of maltreatment chronicity in time. It would have been interesting to see how chronicity linked to maltreatment may be an indicator of the subsequent severity of the profiles. Moreover, a direct indicator of stress level (e.g. cortisol level) would have been a relevant variable in the research and would have allowed a more thorough study of the links between chronicity, stress and later impact on the severity of cognitive profiles. Concerning the profiles, the "extended deficits" subgroup consists of only seven subjects, which reduces the range of the results. It would also be interesting to carry out more studies with a larger number of subjects using clusters analysis, in order to verify if results can be stacked. These studies could include other neuropsychological measures so as to cover a larger range of cognitive functions. Finally, the sample of resilient children deserves particular attention which should be studied more in-depth by future research. 


\section{Conclusion}

Overall, results of this study allow clinical suggestions. They first support the importance of creating cognitive stimulation programs to prevent cognitive deficits in at-risk populations. They also support the development of cognitive remedial programs based on specific needs of neglected children to offset the difficulties and leads to the development of compensatory strategies. Finally, they justify an alliance among different intervention specialists to provide support within a continuity of services.

\section{References}

1. Cicchetti D, Manly JT (2001) Editorial: Operationalizing child maltreatment: Developmental processes and outcomes. Development and Psychopathology 13: 755-7.

2. De Bellis MD (2001) Developmental traumatology: the psychobiological development of maltreated children and its implications for research, treatment and policy. Dev Psychopathol 13: 539-64.

3. Eckenrode J, Laird M, Doris J (1993) School performance and disciplinary problems among abused and neglected children. Developmental Psychology 29: 53-62. 4. Gaudin JM (1999) Child neglect: Short-term and long-term outcomes. In H. Dubowitz (Ed.), Neglected children: Research, practice, and policy 89-108. Thousand Oaks: Sage.

5. Kinard EM (1999) Psychosocial resources and academic performance in abused children. Children and Youth Services Review 21: 351-76.

6. De Bellis MD (2005) The Psychobiology of Neglect. Child Maltreat 10: 150-72.

7. Glaser D (2000) Child abuse and neglect and the brain--A review. J Child Psychol Psychiatry 41: 97-116.

8. Van der Kolk BA (2003) The neurobiology of childhood trauma and abuse. Child and Adolescent Psychiatric Clinics of North America 12: 293-317.

9. Davis AS, Moss LE, Nogin MM, Webb NE (2015) Neuropsychology of child maltreatment and implications for school psychologists. Psychology in the Schools 52: 77-91.

10. Dileo, JF, Brewer W, Northam E, Yucel M, Anderson V (2017) Investigating the neurodevelopmental mediators of aggression in children with a history of child maltreatment: An exploratory field study. Child Neuropsychology 23: 655-77.

11. Watts-English T, Fortson BL, Gibler N, Hooper SR, De Bellis MD (2006) The psychobiology of maltreatment in childhood. Journal of Social Issues 62: 717-36. 12. De Bellis MD, Hooper SR, Spratt EG, Woolley DP (2009) Neuropsychological findings in childhood neglect and their relationships to pediatric PTSD. J Int Neuropsychol Soc 15: 868-78.

13. Nolin P, Éthier LS (2007) Using neuropsychological profiles to classify neglected children with or without physical abuse. Child Abuse Negl 31: 631-43.

14. Trocme NM, MacLaurin BJ, Fallon BA, Daciuk JF, Billingsley DA, et al. (2001) Canadian Incidence Study of Reported Child Abuse and Neglect Ottawa: Minister of Public Works and Government Services Canada.

15. Beers SR, De Bellis MD (2002) Neuropsychological function in children with maltreatment-related posttraumatic stress disorder. Am J Psychiatry, 159: 483-6. 16. Prasad M, Kramer L, Ewing-Cobbs L (2005) Cognitive and neuroimaging findings in physically abused preschoolers. Arch Dis Child 90: 82-5.

17. Teicher MH, Anderse SL, Polcari A, Anderson CM, Navalta CP, et al. (2003) The neurobiological consequences of early stress and childhood maltreatment. Neurosci Biobehav Rev 27: 33-44.

18. Cicchetti D, Rogosch FA (2001) The impact of child maltreatment and psychopathology on neuroendocrine functioning. Dev Psychopathol 13: 783-804.

19. Cicchetti D, Rogosch F, Lynch M, Holt K (1993) Resilience in maltreated children: Processes leading to adaptive outcome. Development and Psychopathology 5: 629-47.

20. Cicchetti D, Toth SL (2000) Developmental Processes in Maltreated Children. Nebr Symp Motiv 46: 85-160.

21. De Bellis MD, Keshavan MS, Clark DB, Casey BJ, Giedd JN, et al. (1999) Developmental traumatology part II: Brain Development. Biological Psychiatry 45: 1271-84.

22. Allen RE, Oliver JM (1982) The effects of child maltreatment on language development. Child Abuse Negl 6: 299-305.

23. Culp CA, Watkins RV, Lawrence H, Letts D, Kelly DJ, et al. (1991) Maltreated children's language and speech development: Abuse, neglect, and abuse and neglect. First Language 11:377-89.

24. Fox L, Long SH, Langlois A (1988) Patterns of language comprehension deficit in abused and neglected children. J Speech Hear Disord 53: 239-44.

25. Perez C, Widom C (1994) Childhood victimization and long-term intellectual and academic outcomes. Child Abuse Negl 18: 617-33.

26. Strathearn L, Gray PH, O'Callaghan M, Wood DO (2001) Childhood neglect and cognitive development in extremely low birth weight infants: A prospective study. Pediatrics 108: 142-51.

27. Sylvestre A, Mérette C (2010) Language delay in severely neglected children: a cumulative or specific effect of risk factors? Child Abuse Negl 34: 414-28.

28. Nolin P, Banville F, Michallet B (2007) Cognitive functions as adaptation factors and resilience in neglected children. In C Dumont G Kielholfner (Eds), Positive approaches to health (pp.1-21). Nova Science Publishers, Inc.

29. Finkelhor D, Ormrod RK, Turner HA, Hamby SL (2005) The victimization of children and youth: A comprehensive national survey. Child Maltreat 10: 5-25.

30. Kim J, Cicchetti D, Rogosch FA, Manly JT (2009) Child maltreatment and trajectories of personality and behavioral functioning: implications for the development of personality disorder. Dev Psychopathol 21: 889-912.

31. Turner HA, Finkelhor D, Ormrod R (2006) The effect of lifetime victimization on the mental health of children and adolescents. Soc Sci Med 62: $13-27$.

32. Widom CS, DuMont K, Czaja SJ (2007) A prospective investigation of major depressive disorder and comorbidity in abused and neglected children grown up. Arch Gen Psychiatry 64: 49-56.

33. Porter C, Lawson JS, Bigler ED (2005) Neurobehavioral sequelae of child sexual abuse. Child Neuropsychol 11: 203-20.

34. Cicchetti D, Toth SL (1995) A developmental psychopathology perspective on child abuse and neglect. J Am Acad Child Adolesc Psychiatry 34: 541-65.

35. Connor DF, Doerfler LA, Volungis AM, Steingard RJ, Melloni RHJr (2003) Aggressive behavior in abused children. Ann N Y Acad Sci 1008: 79-90.

36. Famularo R, Kinscherff R, Fenton T (1992) Psychiatric diagnoses of maltreated children: preliminary findings. J Am Acad Child Adolesc Psychiatry 31: 863-7.

37. McNally RJ (1998) Experimental approaches to cognitive abnormalities in posttraumatic stress disorder. Clin Psychol Rev 18: 971-82. 
38. Barkley RA (1997) Behavioral Inhibition, sustained attention, and executive functions: Constructing a unifying theory of ADHD. Psychol Bull 121: 65-94. 39. Pennington BF (2005) Toward a new neuropsychological model of Attention-deficit/hyperactivity disorder: Subtypes and multiple deficits. Biological Psychiatry 57: 1221-3.

40. Nigg JT (2005) Neuropsychological theory and findings in Attention Deficit Hyperactivity disorder: The state of the field and salient challenges for the coming decade. Biol Psychiatry 57: 1424-35.

41. Sonuga-Barke E (2005) Caudal models of Attention Deficit/Hyperactivity Dosorder: From common simple deficits to multiple developmental pathways. Biol Psychiatry 57: 1231-8.

42. Howe ML, Cicchetti D, Toth SL, Cerrito BM (2004) True and false memories in maltreated children. Child Dev 75: 1402-17.

43. Howe ML, Goodman GS, Cicchetti D (2008) Stress, trauma, and children’s memory development: Neurobiological, cognitive, clinical, and légal perspectives NY: Oxford University Press.

44. Mark LH, Sheree LT, Dante C (2006) Memory and Developmental Psychopathology. (2nd edn vol.2) pp.629-55.

45. Milner JS (1980) The child abuse potential inventory manual. Webster: Psytec.

46. Milner JS (1986) The child abuse potential inventory manual (2nd edn). Webster: Psytec

47. Palacio-Quintin V, Palacio-Quintin (1992) Version en français du questionnaire CAPI de Milner. Trois-Rivières : GREDEF, Université du Québec à Trois-Rivières (French version of Milner's CAPI questionnaire. Trois-Rivières: GREDEF, University of Quebec at Trois-Rivières.)

48. Hollingshead AB (1957) Two-factors Index of Social Position. New York: Yale.

49. Korkman M, Kirk U, Kemp SL (1998) NEPSY: A developmental neuropsychological assessment. San Antonio: Psychological Corporation.

50. Cohen MJ (1997) Children's Memory Scale. San Antonio, TX: The Psychological Corporation.

51. Lussier F (1996) Normes québécoises du CVLT pour enfants (Quebec norms for the CVLT-C). Unpublished document, St. Justine Hospital, Montreal.

52. Delis D, Kramer J, Kaplan E, Ober A (1994) CVLT-C California Verbal Learning Test for children. Toronto: The Psychological Corporation Harcourt Brace Jovanovich Inc.

53. Wechsler D (1991) Manual for the Wechsler Intelligence Scale for Children-Third Edition (WISC-III). San Antonio, TX: The Psychological Corporation.

54. Korkman M, Kirk U, Kemp S (2003) NEPSY Bilan neuropsychologique de l’enfant. Manual. Toronto: Psychological Corporation (NEPSY Neuropsychological assessment of the child. Manual. Toronto: Psychological Corporation).

55. Hair JF, Black WC (2002) Cluster Analysis. In: LG Grimm PR Yarnokd (Eds), Reading and understanding more multivariate statistics (pp. 147-205), Washington: American Psychological Association.

56. Morris R, Blashfield R, Satz P (1981) Neuropsychology and cluster analysis: Potentials and problems. Journal of Clinical Neuropsychology 3: 79-99.

57. Aldenderfer MS, Blashfield RK (1984) Cluster Analysis. Beverly Hills: Sage.

58. Borgen FH, Barnett DC (1987) Applying cluster analysis in counselling psychology research.J Couns Psychol34: 456-68.

59. Lorr M (1983) Cluster analysis for social scientists. San Francisco: Jossey-Bass.

60. Milligan GW (1980) An examination of the effects of six types of error perturbation on fifteen clustering algorithms. Psychometrika 45: 325-42.

61. Blashfield RK (1976) Mixture Model tests of cluster analysis: Accuracy of four agglomerative hierarchical methods. Psychological Bulletin 83: 377-88.

62. Milligan GW, Hirtle SC (2003) Clustering and classification methods. In J Schinka W Velicer (Eds), Handbook of Psychology: Research Methods in Psychology (vol.2) pp.165-86.. Hoboken: Wiley.

63. Skinner HA (1978) Differentiating the contribution of elevation, scatter and shape in profile similarity. Educational and Psychological measurement 38: 297-308. 64. Adams, Kenneth M (1985) Theoretical, methodological, and statistical issues. In: B.P. Rourke (Edn), Neuropsychology of learning disabilities: Essential of subtype analysis,New York: Guilford, (pp. 17-39).

65. Everitt BS (1980) Cluster Analysis ( $2^{\text {nd }}$ edn.) NY: Halstead Press.

66. Everitt BS (1993) Cluster Analysis ( $3^{\text {rd }}$ edn.) NY: Halstead Press.

67. Mottram L, Donders J (2006) Cluster subtypes on California verbal learning test-children version after pediatric traumatic brain injury. Dev Neuropsychol 30: 865-83.

68. Delis DC, Kramer JH, Kaplan E, Ober BA (1987) California Verbal Learning Test: Adult Version: Manual. Psychological Corporation, San Antonio, Tex. 69. Barkley RA (1995) Linkages between attention and executive functions. In GR Lyon NA Krasnegor (Eds.), Attention, memory, and executive functions (pp.307-326). Baltimore: Paul H. Brookes.

70. Denkla MB (1994) Measurement of executive function. In G. R. Lyon (Eds.), Frames of reference for the assessment of learning disabilities: New views on measurement issues (pp.117-142). Baltimore: Paul H. Brookes.

71. Douglas VL (1988) Cognitive deficits in children with attention deficit disorder with hyperactivity. In LM Bloomingdale JA Sergeant (Eds.), Attention deficit disorder: Criteria, cognition, intervention (pp. 65-82). London: Pergamon.

72. Pennington BF, Ozonoff S (1996) Executive functions and developmental psychopathology. J Child Psychol Psychiatry 37: 51-87.

73. Couvadelli B (2007) NEPSY profiles in children diagnosed with different subtypes of ADHD. Unpublished thesis, University of North Texas, DAI- B 68/02, p. 1357.

74. Broomand CE (2003) The effects of physical abuse on the development of executive functions in children. Dissertation Abstracts International: Section B: The Science and Engineering, 63(11-B): 5544.

75. Coster W, Chicchetti D (1993) Research on the communicative development of maltreated children: Clinical implications. Topics-in-Language-Disorders 13: $25-38$.

76. Coster WJ, Gersten MS, Beeghly M, Cicchetti D (1989) Communicative functioning in maltreated toddlers. Developmental Psychology 25: 1020-9.

77. Moran P, Eckenrode J (1992) Protective personality characteristics among adolescent victims of maltreatment. Child Abuse Negl 16: 743-54.

78. Bremne J, Vermette DE (2001) Stress and Development: Behavioral and biological consequences. Dev Psychopathol 13: 473-89.

79. Ito Y, Teicher MH, Glod CA, Ackerman E (1998) Preliminary evidence for aberrant cortical development in abused children: a quantitative EEG study. J Neuropsychiatry Clin Neurosci 10: 298-307. 
80. Teicher, MH, Andersen, SL, Polcari A, Anderson C M, Navalta CP (2002) Developmental neurobiology of childhood stress and trauma. Psychiatr Clin North Am 25: 397-426.

81. Schore AN (2001) The effects of early relational trauma on right brain development, affect regulation, and infant mental health. Infant Ment Health J 22: 201-69. 